\title{
Experimental and Stress-Strain Equation Investigation on Compressive Strength of Raw and Modified Soil in Loess Plateau
}

\author{
Youchao Zhang, Yihong Wang, Nana Zhao, and Tianya Wang \\ School of Civil Engineering, Chang'an University, Xian 710061, China \\ Correspondence should be addressed to Yihong Wang; zycgodgod@163.com
}

Received 1 September 2016; Revised 22 November 2016; Accepted 7 December 2016

Academic Editor: Sumin Kim

Copyright ( 2016 Youchao Zhang et al. This is an open access article distributed under the Creative Commons Attribution License, which permits unrestricted use, distribution, and reproduction in any medium, provided the original work is properly cited.

\begin{abstract}
As a special kind of soil is widely distributed in Loess Plateau of northwest China, it is difficult to use for growing crops and has poor structural property. According to local arid climate, the best utilization of the soil is as earthen construction material and it has been used for thousands of years. To research and improve the mechanical properties, the study investigates the response of soil with cement, lime, sand, and straw as admixtures to compressive loading. The influence on compressive strength and ductility of additives in different proportions is compared and analysed. The experimental data is also used for the formulation of dimensionless and generalized models describing the raw soil and modified soil's full stress-strain response. The models can be applied to soil and modified soil in Loess Plateau with variable strength and deformation characteristics and therefore may be exploited for earthen construction design and nonlinear structural analyses.
\end{abstract}

\section{Introduction}

It is estimated that 30 percent of the world's population currently live or work in earthen structures $[1,2]$ and the proportion rises to 36 percent in China. As an environmental friendly material, with superior thermal performance, lower cost, and abundant availability, earthen materials have been used in construction of shelters for thousands of years [3]. Earthen construction is also a part of the world's cultural heritage. The world-famous cave-houses and Hakka residential architecture are typical examples in China, and the unique building culture also influences folk art. Nowadays, the promotion of sustainable development has put pressure on all industries, including the construction industry to use suitable methods to protect the environment. Due to current global concerns for sustainable development that have arisen from extensive environmental problems such as climate change and the impoverishment of resources coupled with the rapid pace of technological advancement within the building sector, interest in alternative building materials such as earth has developed [4-6]. Researches on earthen construction and local soil as building material have received growing attention from the scientific community in the past 20 years.
As one of traditional building materials, the soil in the Loess Plateau region which is widely distributed in the northwest of China, different from soil in other regions of China (northeastern black soil, northern rocky mountain soil, southeastern red soil, etc.), is difficult to be used for growing crops. This kind of soil is highly collapsible, which will lead to serious distortion and asymmetrical settlement, so that the Loess Plateau became one of the most serious soil erosion regions all over the world. And this is another reason why this kind of soil has been used as building material for thousands of years. However, the characteristics of soil in Loess Plateau also lead to poor structural properties and adversely affect the seismic performance of local earthen constructions. For seeking sustainable development, one of the key issues is how to make use of the loess resource in northwest China and improve the mechanical property as building material.

A reliable assessment of the material's compressive strength, as well as of its stress-strain response, is required in efficient design and appraisal of earthen structures. For many centuries, construction based on unbaked earth had developed to take advantage of the material's relatively high compressive strength. Though other parameters, such as density, frost resistance, and water absorption, may be 
TABLE 1: Mass ratio of additives in specimens.

\begin{tabular}{lcccc}
\hline Admixture & Cement & Sand & Lime & Straw \\
\hline \multirow{3}{*}{ Mass ratio } & $4 \%$ & $5 \%$ & $5 \%$ & $0.5 \%$ \\
& $8 \%$ & $15 \%$ & $10 \%$ & $1 \%$ \\
& $12 \%$ & $25 \%$ & $15 \%$ & \\
\hline
\end{tabular}

specified in design, compressive strength has become a basic and generally accepted unit of measurement to specify the quality of materials [7]. Minke suggested that, for dry building elements made of earth, a compressive strength of 2-5 MPa should be required [8]. Significant researches have been conducted to examine the possibility of improving the mechanical properties of soil modified by adding varying percentages of admixtures [3, 9, 10]. However, different from other building materials, there is a distinct lack of formal technical guidance concerning the laboratory testing of compression test procedures for soil material $[11,12]$. The mechanical properties of materials are affected by the method of specimen fabrication, dimensional effects, the chosen loading system, and whether specimens are tested wet or dry.

According to the dry climate of northwest China, to obtain the best performance of soil materials, the soil in Loess Plateau was traditionally compacted into walls at optimum moisture content (OMC) nearby. In the past, the soil material might be mixed with a little additive in some cases that maybe wheat straw, lime, or even sand which depend on local conditions. This paper investigates experimentally compressive behaviour of raw soil and modified soil specimens produced at OMC. The modified soil specimens include soil with cement, lime, sand, and straw in different proportion independently. The results are used to formulate nondimensionalized models which are capable of describing the full stress-strain response. Based on that, the generalized stress-strain equations are proposed for design purpose and widespread application. The outcomes of this work are deemed particularly useful to researchers and practitioners working in the field of earthen construction and soil material.

\section{Materials and Methods}

2.1. Materials. For the specimens' production, the soil materials are obtained from the suburb of Yanan city located in Loess Plateau which is the typical sample of Chinese northwest loess and often used locally as construction material. Besides the traditional additives (lime, sand, and straw), Ordinary Portland Cement was also adopted for this study. The mass ratio of every additive is under three different proportions and determined by related researches or traditional ways (shown in Table 1). Among them, the specimens of soil with $1.5 \%$ straw cannot be fabricated due to unconsolidated materials. Thus, there are 12 groups of raw soil and modified soil specimens and each group consisted of 10 specimens. Cement was grade OPC 32.5 (Yaoxian Cement Plant) and other materials were sourced locally. The straw was dried wheat straw and chopped into lengths of $20 \mathrm{~mm}$ to $30 \mathrm{~mm}$ before mixed.
2.2. Preparation of Test Specimens. Before mixed, the natural soil constituents were prepared by initially being air-dried and then the lumps of dried soil were broken down manually and then sieved to remove particles exceeding $4.75 \mathrm{~mm}$ in laboratory. To obtain a stabilised soil, a homogeneous mixture was made by blending the required amount of additive with sifted soil in a tray before adding water. The required amount of water was obtained based on the OMC of raw soil and modified soil which was evaluated by test (Table 2 ).

Based on the current geotechnical engineering test method and criteria (GB/T 50123-1999) [13], the well-blended mixture was poured into three layers to be compacted in a mould of internal diameter $102 \mathrm{~mm}$ and height $116 \mathrm{~mm}$ with a collar of $70 \mathrm{~mm}$ attached thereto (Figure 1). The compaction energy was $604 \mathrm{~kJ} \cdot \mathrm{m}^{-3}$, which was consistent with Chinese and other international standards. After that, the collar was removed and the extra soil was trimmed to make it level with the top of the mould. Then the specimens were demoulded and air-dried under the laboratory conditions at $20-25^{\circ} \mathrm{C}$ for 60 days before testing the compressive strength (Figure 2). The size of the cylindrical specimens was $102 \mathrm{~mm}$ in diameter and $116 \mathrm{~mm}$ in height.

2.3. Testing of Compressive Strength. The compressive tests were undertaken in the Building Material Laboratory at Changan University. A universal compression testing machine (YA-300) with a maximum load of $300 \mathrm{kN}$ was used in the testing procedure to apply stress at a rate of $0.1 \mathrm{kN} \cdot \mathrm{s}^{-1}$. The load-displacement curves were output by the electrohydraulic servocontrol system (GTC350).

\section{Experimental Results and Discussion}

3.1. Modes of Failure in Compression. Compressive failure of cylinders was characterized by bulging and formation of near-vertical surface cracks [11]. Accordingly, the failure modes can be divided into three categories: raw soil, sand soil, and straw soil. Those of cement soil and lime soil are basically similar with raw soil (Figure 3). In this category, cracks occurred at the top of the specimens and then extended to the middle. At maximum compressive stress, several vertical cracks ran through the whole specimen and the blocks between vertical cracks spalled off (Figure 3(a)). The remains of the specimen were similar and in the shape of an hourglass (Figure 3(b)). Besides, cement soil specimens were of better quality and the cracks therein appeared later than those in specimens of raw soil and lime soil.

For sand soil, after cracks appeared, there were more vertical cracks which were distributed evenly over the sample surface. While at maximum compressive stress, there were obviously more vertical cracks than raw soil at the sample surface (Figure 4(a)). But the exfoliation of specimens was less than raw soil specimens during failure process, and the diameter of failure specimens is lager (Figure 4(b)).

Differing from other groups, straw specimens had a larger deformation at maximum compressive stress. And the specimens did not instantly fail after that, and they were subjected to significant additional deformation before structural collapse (Figure 5(a)). The wheat straw in specimens snapped 
TABLE 2: OMC of raw soil and modified soil.

\begin{tabular}{|c|c|c|c|c|c|c|c|c|c|c|c|c|}
\hline \multirow{2}{*}{ Modified soil } & \multirow{2}{*}{ Raw soil } & \multicolumn{3}{|c|}{ Cement } & \multicolumn{3}{|c|}{ Lime } & \multicolumn{3}{|c|}{ Sand } & \multicolumn{2}{|c|}{ Straw } \\
\hline & & $4 \%$ & $8 \%$ & $12 \%$ & $5 \%$ & $10 \%$ & $15 \%$ & $5 \%$ & $15 \%$ & $25 \%$ & $0.5 \%$ & $1 \%$ \\
\hline Optimum moisture content $/ \%$ & 18.2 & 19.8 & 20.4 & 21.4 & 22.0 & 22.1 & 22.2 & 17.4 & 17.4 & 17.2 & 18.3 & 18.4 \\
\hline Maximum dry density/g $\mathrm{cm}^{-3}$ & 1.72 & 1.69 & 1.67 & 1.67 & 1.58 & 1.57 & 1.56 & 1.75 & 1.78 & 1.79 & 1.68 & 1.65 \\
\hline
\end{tabular}

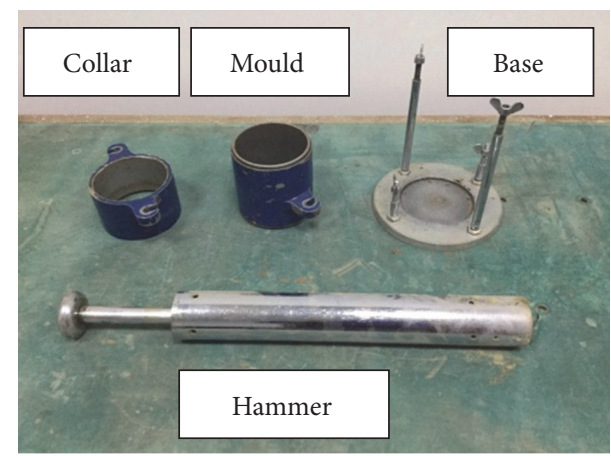

(a) Components of mould

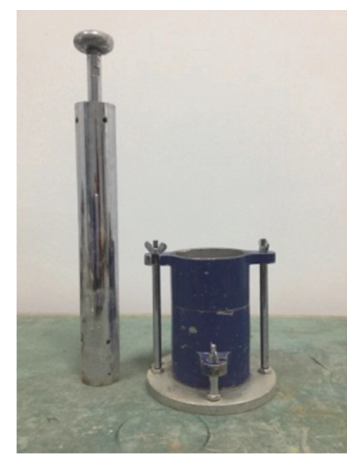

(b) Assembled mould

FIGURE 1: Mould of specimens.

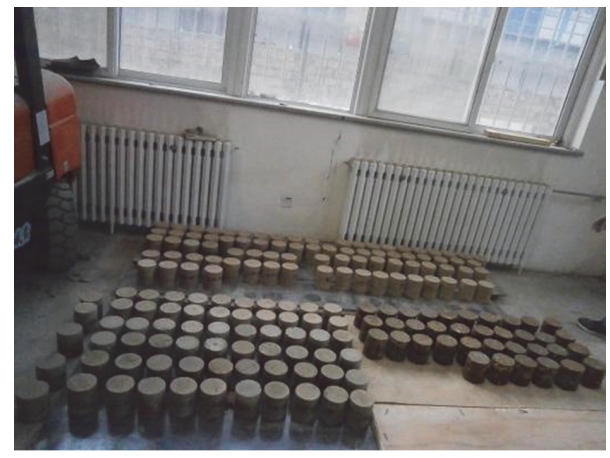

FIgURE 2: Air-cured specimens.

and could be heard in all loading process. Following the completion of the compression tests, the specimens had not fully disintegrated (Figure 5(b)). This can be justified, to some extent: straw fibres held together some significant parts of the soil matrix, delaying failure.

\subsection{Stress-Strain Behaviour and Ultimate Compressive Stren-} gth. Test results are summarized in Table 3. Compression stress-strain curves were plotted and one typical curve for raw soil and each kind of additive are picked up and shown in Figure 6, to contrast the effects of different additive.

The compressive strength of raw soil reached $3.10 \mathrm{MPa}$ and the peak strain was 0.00202. Actually, the strength is generally acceptable but of high discreteness with the variation coefficient 0.1947 . It means, as building material, raw soil has an unstable mechanical property, while the variation coefficient of other modified soil groups all decreased significantly that is around 0.1 basically.
There is obvious effect of cement to improve the compressive strength and specimens of soil with $12 \%$ cement had the best compressive strength in the test $(6.55 \mathrm{MPa}$, an increase of up to $111.3 \%$ compared with raw soil). Data produced by various researchers show linear correlation between compressive strength and cement content [7] which also exists in this test. The peak strain was unaffected by cement content and kept 0.020 around same as raw soil (not exceed 5\%). As a typical inorganic cementitious mineral, the cement reacts with active silica and alumina in loess microspheres and then converted them into calcium silicate hydrate $(\mathrm{CSH})$ gel and calcium aluminate hydrate $(\mathrm{CAH})$ gel [14]. These water-stable compounds can improve the compressive strength of earthen materials by increasing the bond strength between internal structures.

Sand added to the loess can improve the gradation and the quality of the earthen construction material and then improved its compressive strength. The effect, in magnitude, ranked second to that of cement, and the strain increased by sand content. Similar to coarse aggregate in concrete, there is an optimal proportion for improving the degree of density. Therefore, in the test, the compressive strength first increases and then decreases with the increase of sand content and soil with $15 \%$ sand got the highest strength.

The straw added to the soil cannot increase the compressive strength but, as a reinforcing agent, the deformability of specimens was better than any other groups. As the cracks are growing, straw hindered relative slippage of damaged sections and prevented soil block deformation, thus restraining crack development and improving the ultimate strain. The peak strain of soil with $1.0 \%$ straw was 0.0423 which has an increase of $109.4 \%$ compared with raw soil.

The lime reacts with the moisture in the soil and the compounds created in hydration reaction can improve the 


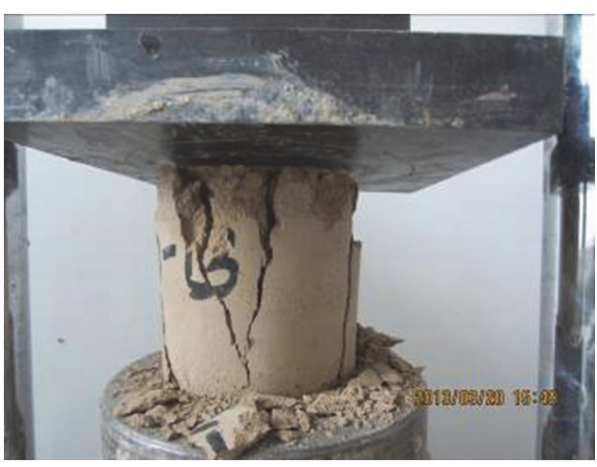

(a) Ultimate load

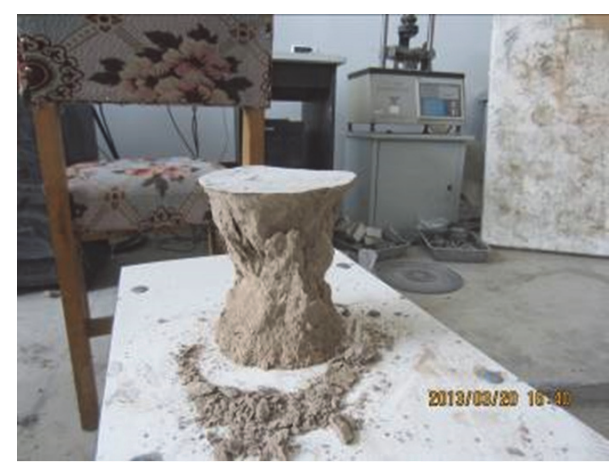

(b) Failure mode

FIgURE 3: Raw soil, cement soil, and lime soil specimens.

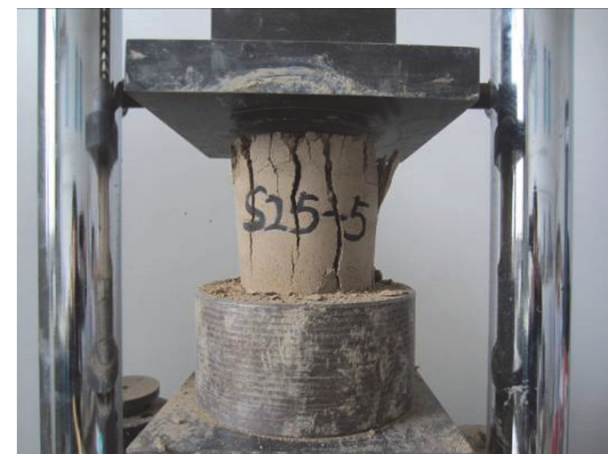

(a) Ultimate load

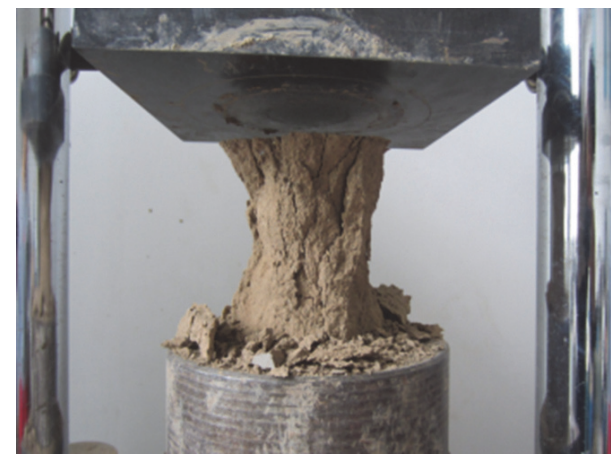

(b) Failure mode

FIgURE 4: Sand soil specimens.

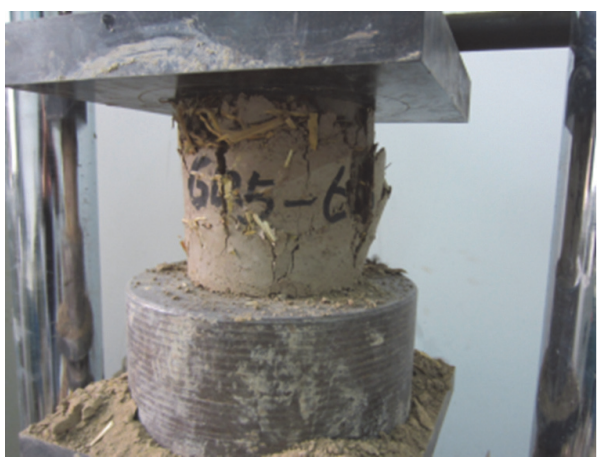

(a) Ultimate load

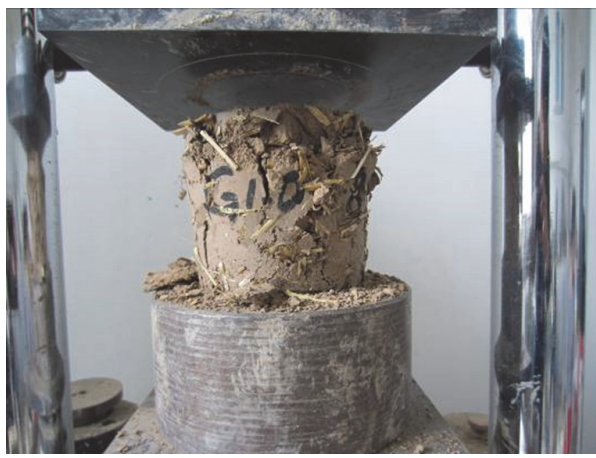

(b) Failure mode

FIGURE 5: Straw soil specimens.

TABLE 3: Mean compressive strength and peak strain.

\begin{tabular}{|c|c|c|c|c|c|c|c|c|c|c|c|c|}
\hline \multirow{2}{*}{ Modified soil } & \multirow{2}{*}{ Raw soil } & \multicolumn{3}{|c|}{ Cement } & \multicolumn{3}{|c|}{ Lime } & \multicolumn{3}{|c|}{ Sand } & \multicolumn{2}{|c|}{ Straw } \\
\hline & & $4 \%$ & $8 \%$ & $12 \%$ & $5 \%$ & $10 \%$ & $15 \%$ & $5 \%$ & $15 \%$ & $25 \%$ & $0.5 \%$ & $1.0 \%$ \\
\hline Cracking load $/ \mathrm{kN}$ & 13.82 & 18.13 & 32.54 & 33.29 & 12.95 & 12.67 & 11.98 & 15.47 & 16.26 & 15.33 & 10.89 & 10.24 \\
\hline Ultimate load/kN & 25.32 & 34.88 & 43.86 & 53.49 & 25.32 & 25.24 & 25.40 & 37.00 & 37.65 & 36.91 & 25.56 & 24.99 \\
\hline Ultimate compressive strength/MPa & 3.10 & 4.27 & 5.37 & 6.55 & 3.10 & 3.09 & 3.11 & 4.53 & 4.61 & 4.52 & 3.13 & 3.06 \\
\hline Variation coefficient $/ \%$ & 19.47 & 9.94 & 12.89 & 8.11 & 11.43 & 9.07 & 6.15 & 10.85 & 7.39 & 3.77 & 7.45 & 8.04 \\
\hline Peak strain/\% & 2.02 & 2.04 & 2.08 & 1.90 & 1.67 & 2.08 & 2.63 & 2.12 & 2.33 & 2.69 & 2.97 & 4.23 \\
\hline
\end{tabular}




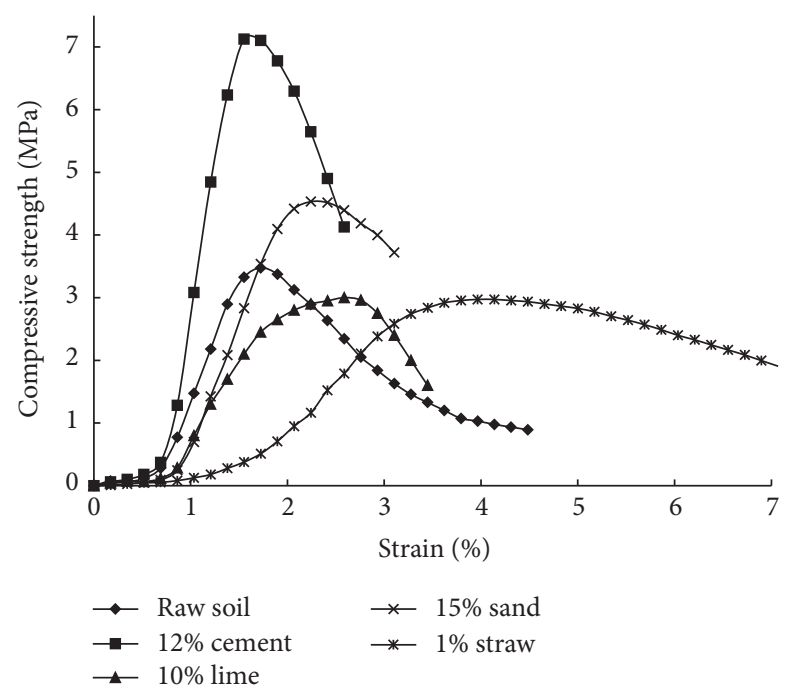

FIGURE 6: Stress-strain curves: specimens with different admixtures.

bonding with soil particles [15]. But, in this test, no matter specimens with $5 \%, 10 \%$, and $15 \%$ lime, the mean compressive strength shows no increasing and the peak stain has no obvious regularity, either. It might be related to low levels of moisture content in soil sample. It is shown that the lime is not suitable for being added in soil in Loess Plateau as building materials, at least, as additive alone.

\section{Stress-Strain Relationship under Uniaxial Compression}

4.1. Nondimensionalized Stress-Strain Equation. Using results obtained from tests, stress-strain relations describing raw soil and soil with cement, sand, and straw responses to compressive loading were developed. To propose equations applicable to soil of Chinese northwest loess with varying load-bearing and deformation capacities, stress and strain values were normalised. Hence, the stress and strain of each specimen were dealt with by a dimensionless method: the normal stress $\sigma_{\mathrm{c}}$ was divided by the peak stress $\sigma_{0}\left(y=\sigma_{\mathrm{c}} / \sigma_{0}\right)$ and the axial strain $\varepsilon_{\mathrm{c}}$ was divided by the peak strain $\varepsilon_{0}(x=$ $\left.\varepsilon_{\mathrm{c}} / \varepsilon_{0}\right)$.

In previous researches on soil material or adobe, thirdorder polynomials were often adopted to capture the nonlinear behaviour in the rising step $[11,16]$. But, in this test, polynomial function was found not to accurately describe the concave down at the beginning of loading. Therefore, in this paper, a quadratic exponential function was used to fit the rising step of soil and modified soil curves. To ensure the validity of the equations, the following constraints were imposed: (a) the curves passed through the origin $(x=y=$ $0)$, (b) the curves passed the point at which $\sigma_{c}=\sigma_{0}$ and $\varepsilon_{\mathrm{c}}=\varepsilon_{0}(x=y=1)$, and (c) the ascending branch and descending branch were considered as two separate strain intervals and the continuity of the curve is enforced at their common point $(x=y=1)$. The optimization problem was solved using standard MATLAB optimization routines, which yield the following fitted curves.

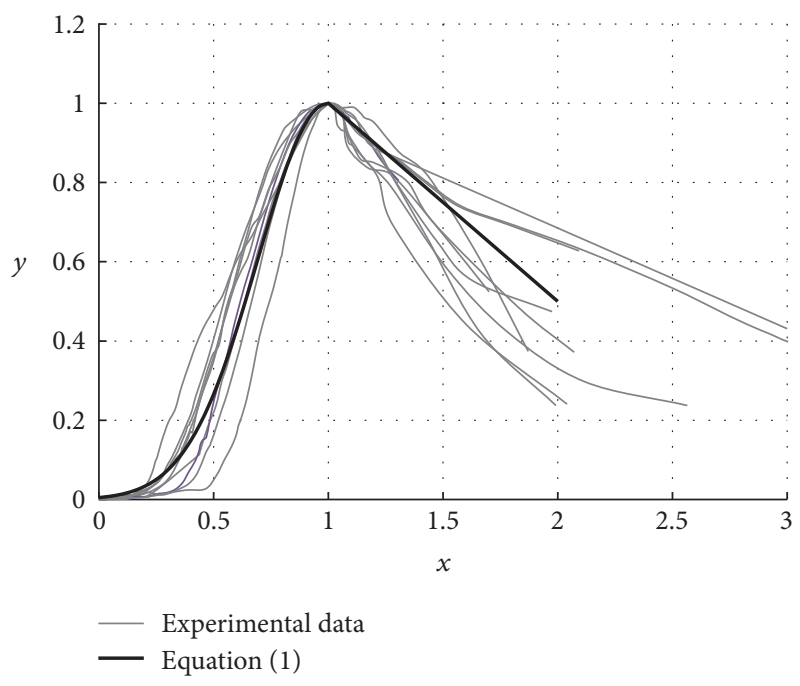

FIGURE 7: Dimensionless stress-strain curves: raw soil.

(1) Raw Soil and Cement Soil

$$
y= \begin{cases}e^{-5.3(x-1)^{2}} & (x \leq 1) \\ 1.5-0.5 x & (x \geq 1)\end{cases}
$$

By comparing (1) with experimental data from raw soil, a satisfactory $R^{2}$ of 0.90 was achieved, which indicated that stresses are well predicted by (1), as is graphically verified in Figure 7.

With the different percentage of cement, the cement soil specimens were showed to be similar to the raw soil during the load process (Section 3.1). By the calculation, (1) was also applied to cement soil and, compared with experimental data, $R^{2}$ of $4 \%, 8 \%$, and $12 \%$ cement soil was $0.96,0.88$, and 0.92 , respectively. It indicated that the stress-strain relationship of cement soil was matched well with (1), especially for the rising step. An excellent correspondence similar to Figure 8 was obtained.

(2) Sand Soil. The dimensionless stress-strain curves of sand soil and straw soil were inapplicable with (1). Parameter $m_{\mathrm{s}}$ of the rising part is brought into the model and (2) derived as follows:

$$
y= \begin{cases}e^{\left(-5.3+0.02 m_{\mathrm{s}}\right) \times(x-1)^{2}} & (x \leq 1) \\ 1.5-0.5 x & (x \geq 1)\end{cases}
$$

$m_{\mathrm{s}}$ is the mass percentage of sand in the specimen. Here, $m_{\mathrm{s}}$ in $5 \%, 15 \%$, and $25 \%$ sand soil specimens was 5,15 , and 25 , respectively. For $m_{s}=0,(2)$ is transformed into (1). The graphical representation of (2) and normalised stress-strain experimental data are shown in Figure 9. The determination coefficient $R^{2}$ reached $0.96,0.88$, and 0.91 for $5 \%, 15 \%$, and $25 \%$ sand soil, respectively. 


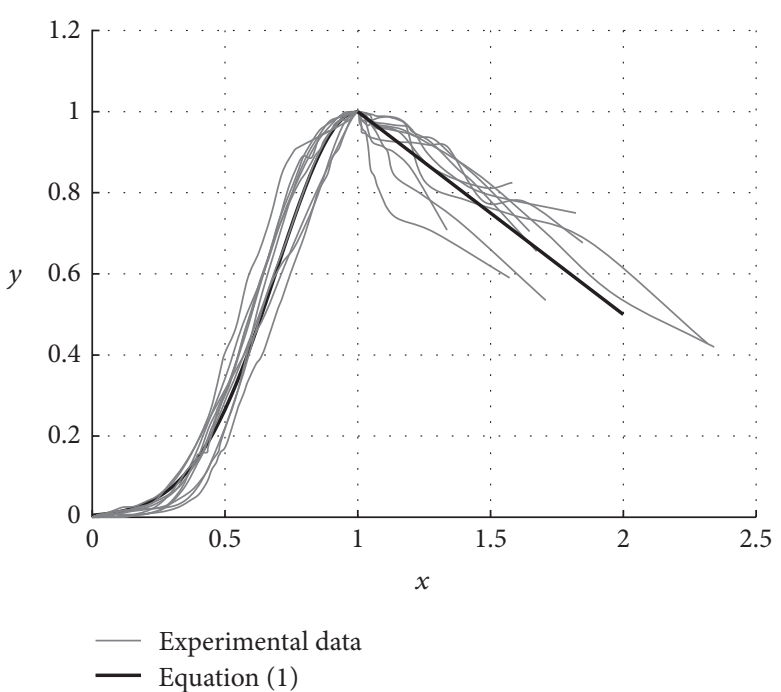

(a) $4 \%$ cement

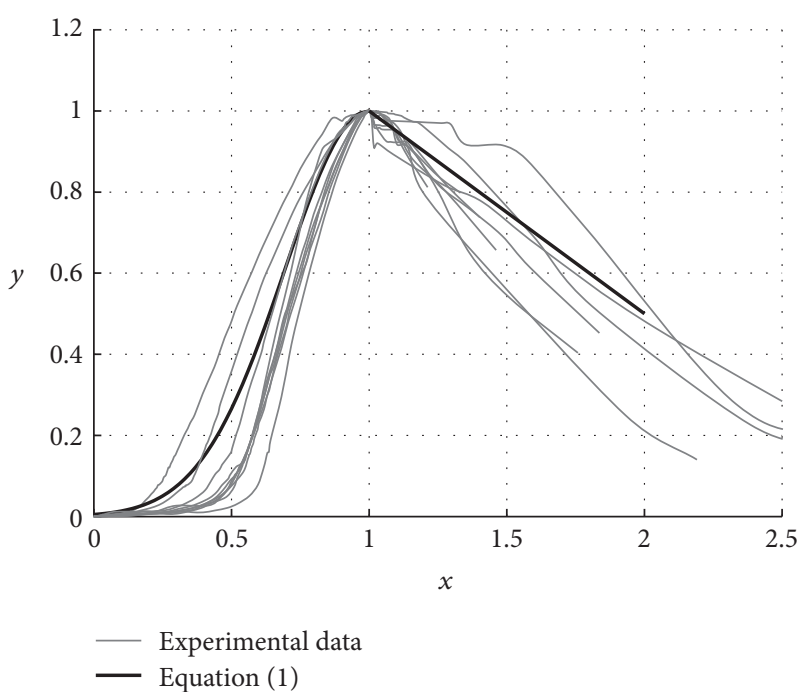

(b) $8 \%$ cement

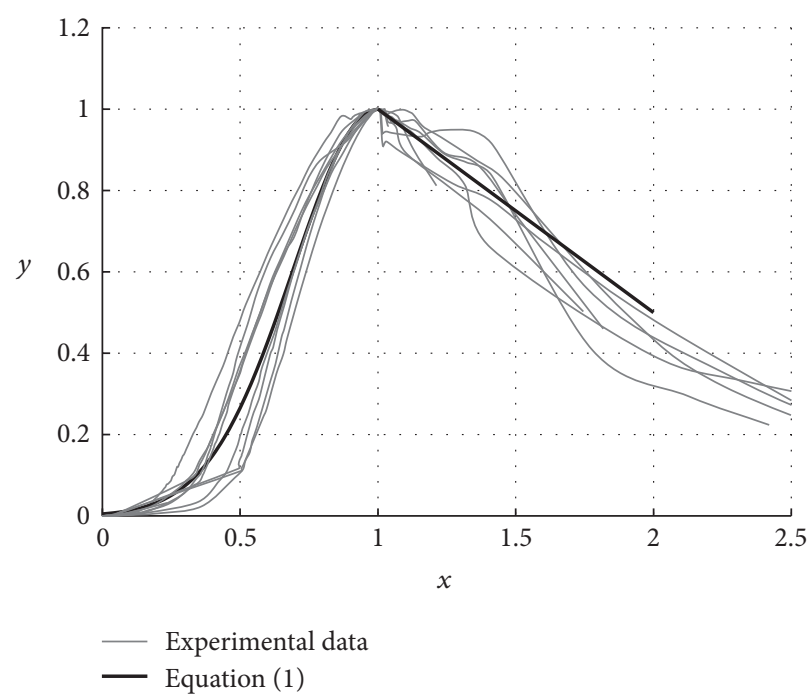

(c) $12 \%$ cement

Figure 8: Dimensionless stress-strain curves of cement soil.

(3) Straw Soil. For straw soil specimens, besides that parameter $m_{\mathrm{st}}$ is brought into the rising part, the descending branch also needed to be adjusted. Equation (3) is as follows:

$$
y= \begin{cases}e^{\left(-5.3+m_{\mathrm{st}}\right) \times(x-1)^{2}} & (x \leq 1) \\ 1.4-0.4 x & (x \geq 1),\end{cases}
$$

where $m_{\mathrm{st}}$ is the mass percentage of straw in a specimen. In this test, $m_{\mathrm{st}}$ of $0.5 \%$ and $1.0 \%$ straw soil specimens was 0.5 and 1.0. Equation (3) matched the experimental data (Figure 10) and a satisfactory $R^{2}$ which reached 0.90 and 0.85 was achieved.

It can be inferred that the rising step of stress-strain curves of soil and modified soil in the test had an increasing tendency which slowed down first and then became faster under compression. The proposed equations can reflect the mechanical properties of soil in Loess Plateau well and support references for other earthen construction materials.

4.2. Generalized Stress-Strain Equations. For design purposes and widespread application, it is necessary to predict the peak compressive strength and strain for raw soil and various modified soil cases. The generalized stress-strain equations for raw soil in Loess Plateau and feasible modified soil are proposed based on the general regularity analysed in Section 3.2 and nondimensionalized equation in Section 4.1.

As mentioned, the peak strain $\varepsilon_{0}$ of raw soil and cement soil with different proportions remains stable and around 0.020. And according to the linear correlation between compressive strength and cement content in the test and other researches, the parameters of cement soil equation were determined (Figure 11). The generalized stress-strain 


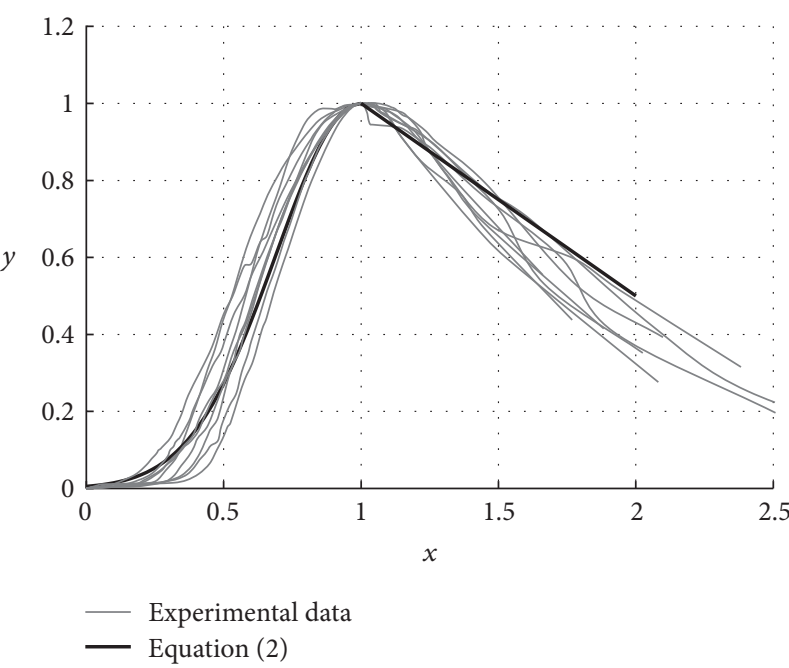

(a) $5 \%$ sand

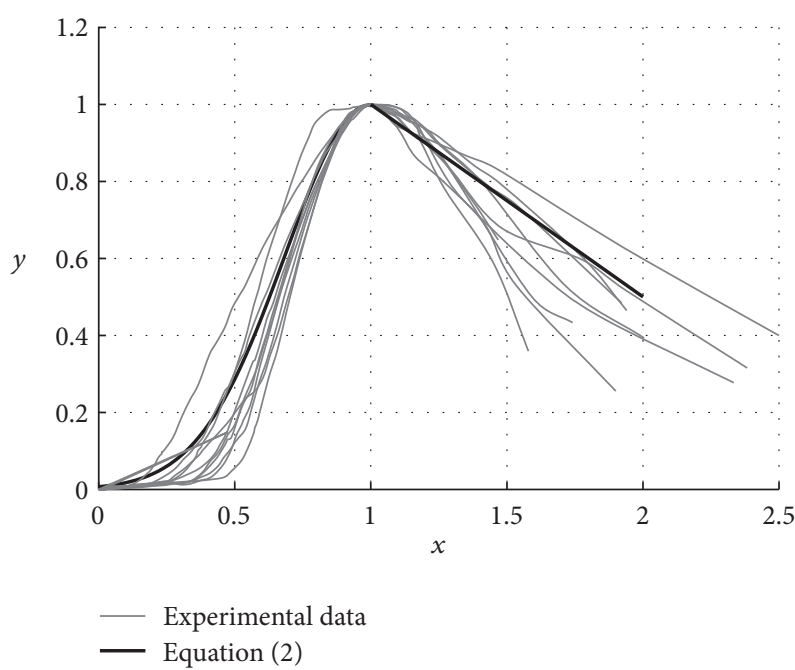

(b) $15 \%$ sand

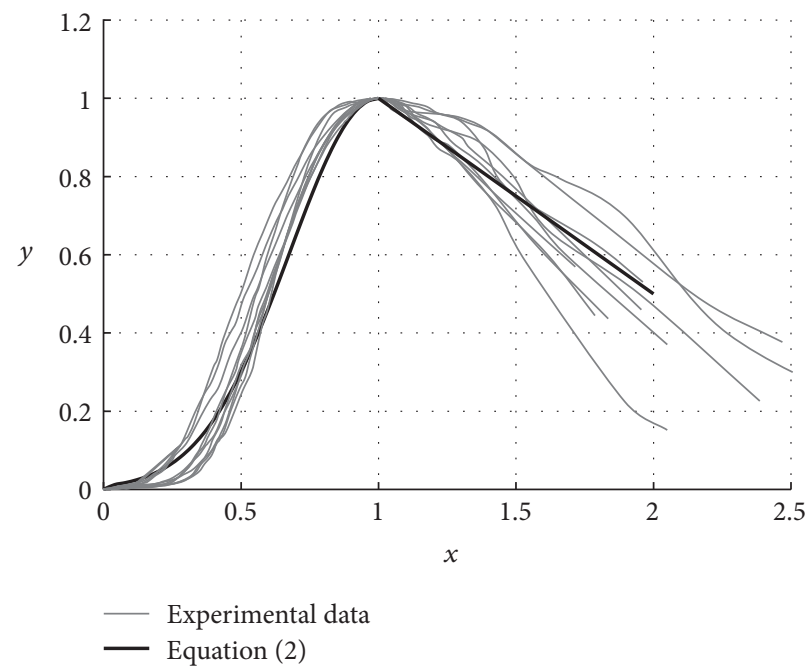

(c) $25 \%$ sand

FIGURE 9: Dimensionless stress-strain curves of sand soil.

equations for raw soil and cement soil are shown in (4)-(6). As $m_{\mathrm{s}}$ and $m_{\mathrm{st}}, m_{\mathrm{c}}$ is the mass percentage of cement in specimens. $m_{c}$ of the $4 \%, 8 \%$, and $12 \%$ cement soil specimens is 4,8 , and 12 . For $m_{c}=0$ which means for soil without cement, (6) is turned into (4).

(1) Raw Soil

$$
\begin{aligned}
\sigma_{\mathrm{r}} & = \begin{cases}3.1 e^{-5.3\left(\varepsilon / \varepsilon_{0}-1\right)^{2}} & \left(\varepsilon \leq \varepsilon_{0}\right) \\
4.65-1.55 \frac{\varepsilon}{\varepsilon_{0}} & \left(\varepsilon \geq \varepsilon_{0}\right),\end{cases} \\
\varepsilon_{0, \mathrm{r}} & =0.020 .
\end{aligned}
$$

(2) Cement Soil

$$
\begin{aligned}
\sigma_{\mathrm{c}} & = \begin{cases}\left(3.1+0.29 m_{\mathrm{c}}\right) e^{-5.3\left(\varepsilon / \varepsilon_{0}-1\right)^{2}} & \left(\varepsilon \leq \varepsilon_{0}\right) \\
\left(3.1+0.29 m_{\mathrm{c}}\right)\left(1.5-0.5 \frac{\varepsilon}{\varepsilon_{0}}\right) & \left(\varepsilon \geq \varepsilon_{0}\right),\end{cases} \\
\varepsilon_{0, \mathrm{c}} & =0.020 .
\end{aligned}
$$

For sand and straw soil, at maximum compressive stress, the peak strain increased with additive content. According to the experimental data, the peak strain of sand soil $\left(\varepsilon_{0, \mathrm{~s}}\right)$ and straw soil $\left(\varepsilon_{0, \mathrm{st}}\right)$ both have linear correlation with additive content (Figure 12). Therefore, the equation of $\varepsilon_{0, \mathrm{~s}}$ and $\varepsilon_{0, \mathrm{st}}$ 


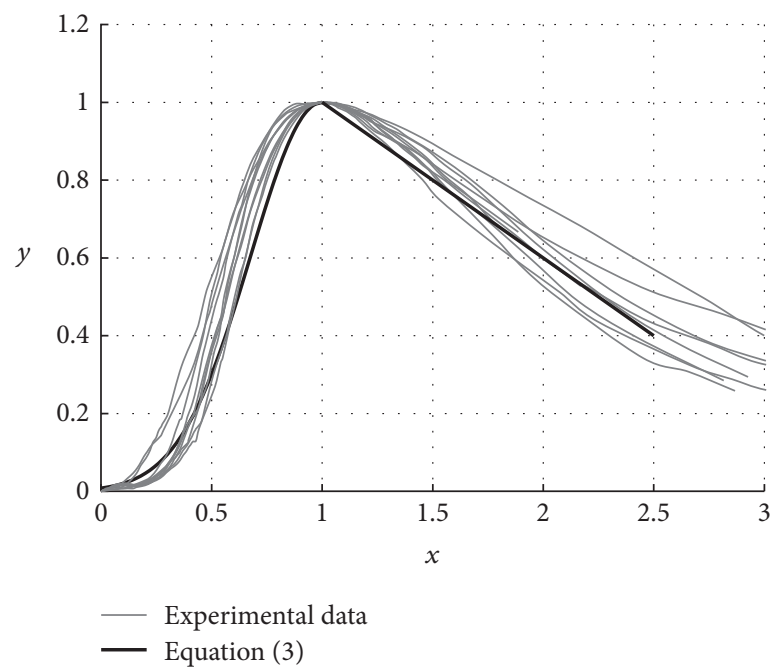

(a) $0.5 \%$ wheat straw

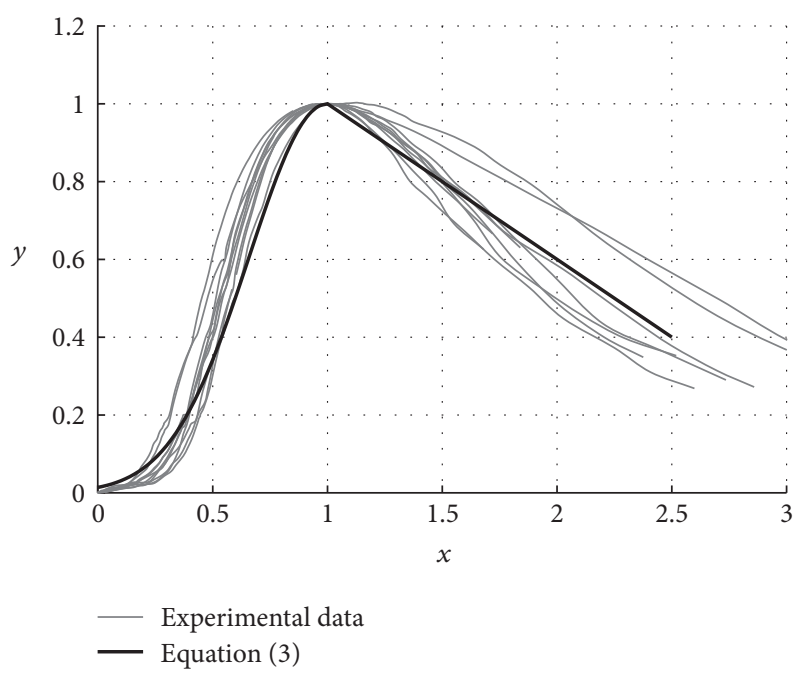

(b) $1 \%$ wheat straw

FIGURE 10: Dimensionless stress-strain curves of straw soil.

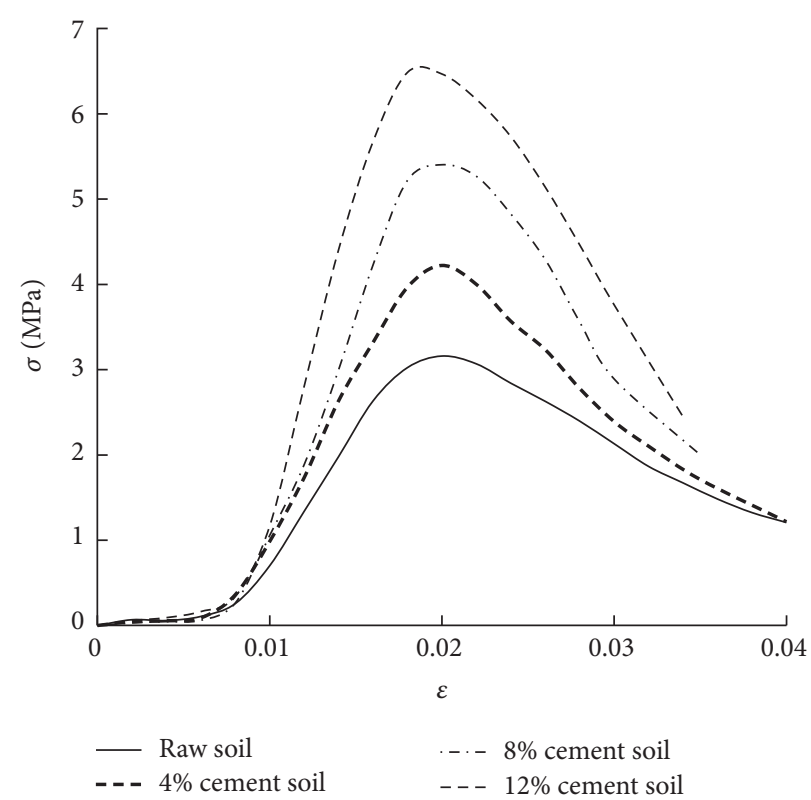

(a) Stress-strain curve

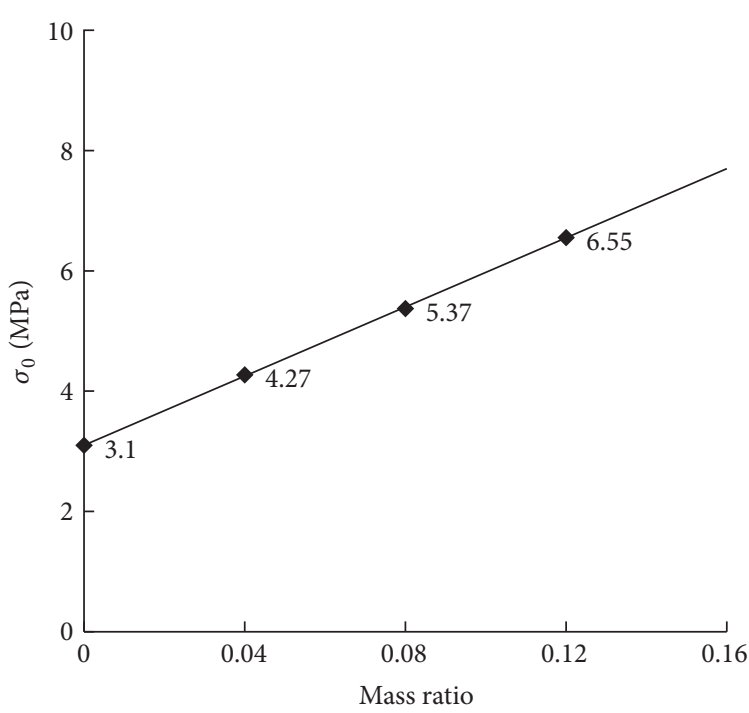

(b) Compressive strength with different cement content

FIGURE 11: Relationships between stress-strain and cement content.

needs to be adjusted by bringing parameter $m_{\mathrm{s}}$ and $m_{\mathrm{st}}$ in (9) and (11). The ultimate compressive strength of straw soil remains unchanged by adding straw content and (10) was given based on (3). For stress-strain equation of soil with sand, as mentioned in Section 3.2, the relationship between stress and sand content does not match the linear trend and the changing laws cannot be convincible determined by three proportions of sand and soil; (8) is given useable only for soil with $15 \%$ sand as it is recommended.
(3) Sand Soil

$$
\begin{aligned}
\sigma_{\mathrm{s}, 15 \%} & = \begin{cases}4.6 e^{\left(-5.3+0.02 m_{s}\right)\left(\varepsilon / \varepsilon_{0}-1\right)^{2}} & \left(\varepsilon \leq \varepsilon_{0}\right) \\
6.9-2.3 \frac{\varepsilon}{\varepsilon_{0}} & \left(\varepsilon \geq \varepsilon_{0}\right),\end{cases} \\
\varepsilon_{0, \mathrm{~s}} & =\left(0.020+0.3 \times 10^{-3} m_{\mathrm{s}}\right) .
\end{aligned}
$$




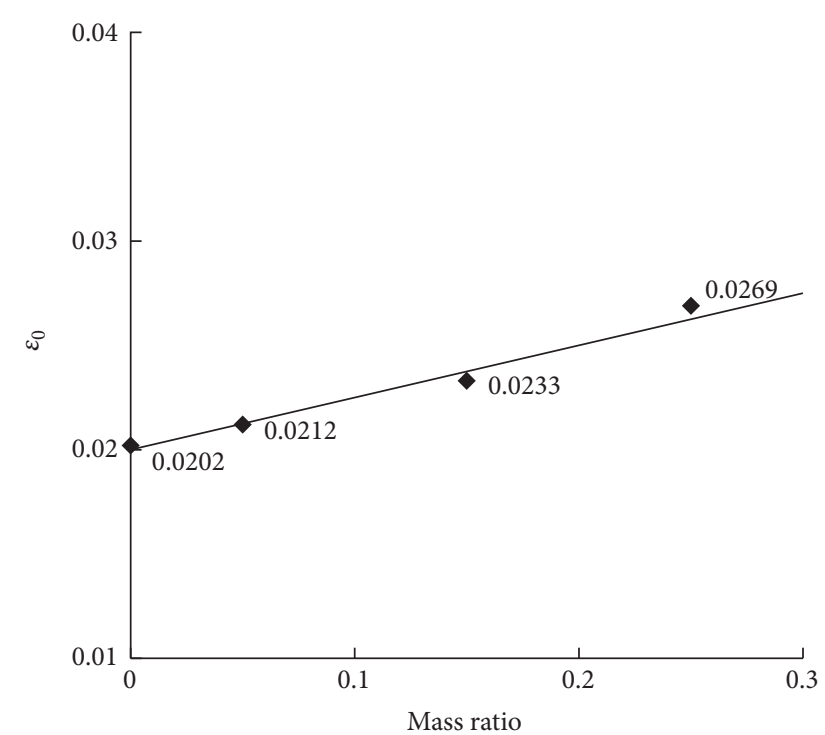

(a) Sand soil

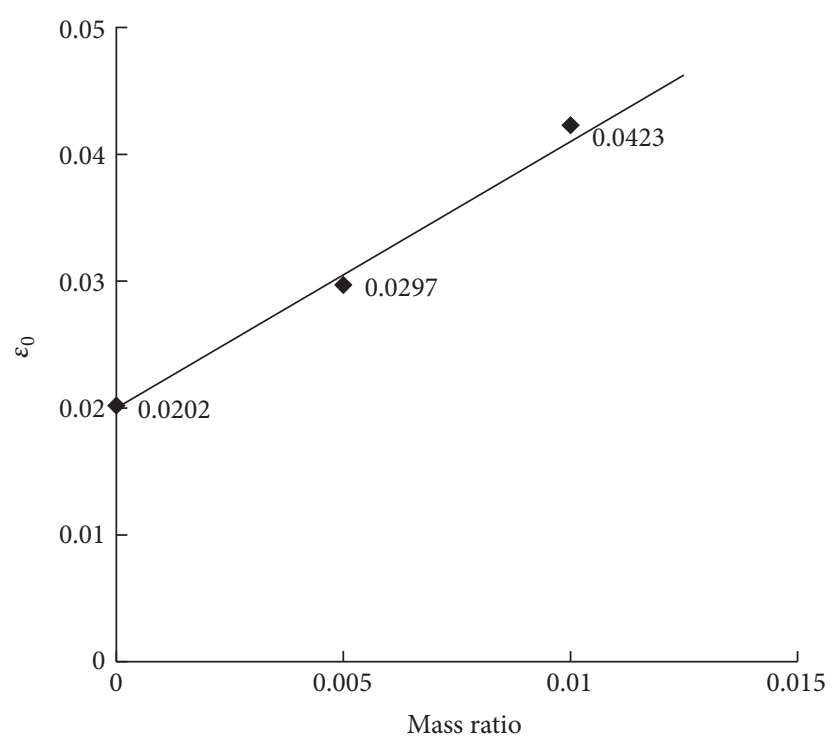

(b) Straw soil

FigURE 12: Relationships between stress and additive content of sand soil and straw soil.

(4) Straw Soil

$$
\begin{aligned}
\sigma_{\mathrm{st}} & = \begin{cases}3.1 e^{\left(-5.3+m_{\mathrm{st}}\right)\left(\varepsilon / \varepsilon_{0}-1\right)^{2}} & \left(\varepsilon \leq \varepsilon_{0}\right) \\
4.34-1.24 \frac{\varepsilon}{\varepsilon_{0}} & \left(\varepsilon \geq \varepsilon_{0}\right),\end{cases} \\
\varepsilon_{0, \mathrm{st}} & =\left(0.020+0.021 m_{\mathrm{st}}\right) .
\end{aligned}
$$

\section{Conclusions}

To improve the mechanical property of soil in Loess Plateau as building material, the experimental research of 120 raw soil and modified soil specimens that were under compression test was carried out. Based on the characteristics of soil and local conditions, specimens were made at OMC and fully dried ( 8 to 10 weeks) in the laboratory. The method and results offer references for the modification of loess and soil in other regions considering the lack of internationally accepted standardised testing procedures specifically referring to unfired clay materials.

The mechanical properties under compression of soil in Loess Plateau and modified soil were obtained. It indicated that cement can significantly improve compressive strength, while the straw fibres were used to improve the ductility of soil material, but the mass ratio of straw should not exceed $1.0 \%$. Sand was added to improve the particle distribution and soil with $15 \%$ sand achieved the best results in the test. Lime is not suitable for being added in this kind of soil as additive alone.

The constitutive model developed for describing the stress-strain behaviour under compression is well-fitted to the experimental data. The dimensionless and generalized model is based on a quadratic exponential function with parameters adjusted for additive content. It is anticipated that the proposed model can have applications in earthen construction designs and analytical nonlinear engineering computations.

\section{Disclosure}

Any opinions, findings, and conclusions or recommendations expressed in this paper are those of the authors and do not necessarily reflect those of the funding agency.

\section{Competing Interests}

The authors declare that they have no competing interests.

\section{Acknowledgments}

The work presented herein was performed with a financial grant from the National Natural Science Foundation of China (51478043).

\section{References}

[1] H. Nirroumand, M. F. M. Zain, and M. Jamil, "Various types of earth buildings," Social and Behavioral Sciences, vol. 89, pp. 226-230, 2013.

[2] R. W. Salim, J. M. Ndambuki, and D. A. Adedokun, "Improving the bearing strength of sandy loam soil compressed earth block bricks using Sugercane Bagasse Ash," Sustainability, vol. 6, no. 6, pp. 3686-3696, 2014.

[3] F. Pacheco-Torgal and S. Jalali, "Earth construction: lessons from the past for future eco-efficient construction," Construction and Building Materials, vol. 29, pp. 512-519, 2012.

[4] I. Demir, "Effect of organic residues addition on the technological properties of clay bricks," Waste Management, vol. 28, no. 3, pp. 622-627, 2008. 
[5] X. Dong, V. Soebarto, and M. Griffith, "Strategies for reducing heating and cooling loads of uninsulated rammed earth wall houses," Energy and Buildings, vol. 77, pp. 323-331, 2014.

[6] M. Bouasker, N. Belayachi, D. Hoxha, and M. Al-Mukhtar, "Physical characterization of natural straw fibers as aggregates for construction materials applications," Materials, vol. 7, no. 4, pp. 3034-3048, 2014.

[7] J.-C. Morel, A. Pkla, and P. Walker, "Compressive strength testing of compressed earth blocks," Construction and Building Materials, vol. 21, no. 2, pp. 303-309, 2007.

[8] G. Minke, Building with Earth, DE GRUYTER, Berlin, Germany, 2009.

[9] P. Walker and T. Stace, "Properties of some cement stabilised compressed earth blocks and mortars," Materials and Structures, vol. 30, no. 203, pp. 545-551, 1997.

[10] B. V. V. Reddy and A. Gupta, "Strength and elastic properties of stabilized mud block masonry using cement-soil mortars," Journal of Materials in Civil Engineering, vol. 18, no. 3, pp. 472476, 2006.

[11] R. Illampas, I. Ioannou, and D. C. Charmpis, "Adobe bricks under compression: experimental investigation and derivation of stress-strain equation," Construction and Building Materials, vol. 53, pp. 83-90, 2014.

[12] S. A. Lima, H. Varum, A. Sales, and V. F. Neto, "Analysis of the mechanical properties of compressed earth block masonry using the sugarcane bagasse ash," Construction and Building Materials, vol. 35, pp. 829-837, 2012.

[13] "Soil testing methods of Chinese standards," Tech. Rep. GB/T50123-1999, Standards China, Beijing, China, 1998.

[14] P. Walker, "Compressive strength of cement stbailized pressed earth blocks," Building Research and Information, vol. 30, pp. 545-551, 1997.

[15] A. Aldaood, M. Bouasker, and M. Al-Mukhtar, "Geotechnical properties of lime-treated gypseous soils," Applied Clay Science, vol. 88-89, pp. 39-48, 2014.

[16] N. Augenti and F. Parisi, "Constitutive models for tuff masonry under uniaxial compression," Journal of Materials in Civil Engineering, vol. 22, no. 11, pp. 1102-1111, 2010. 

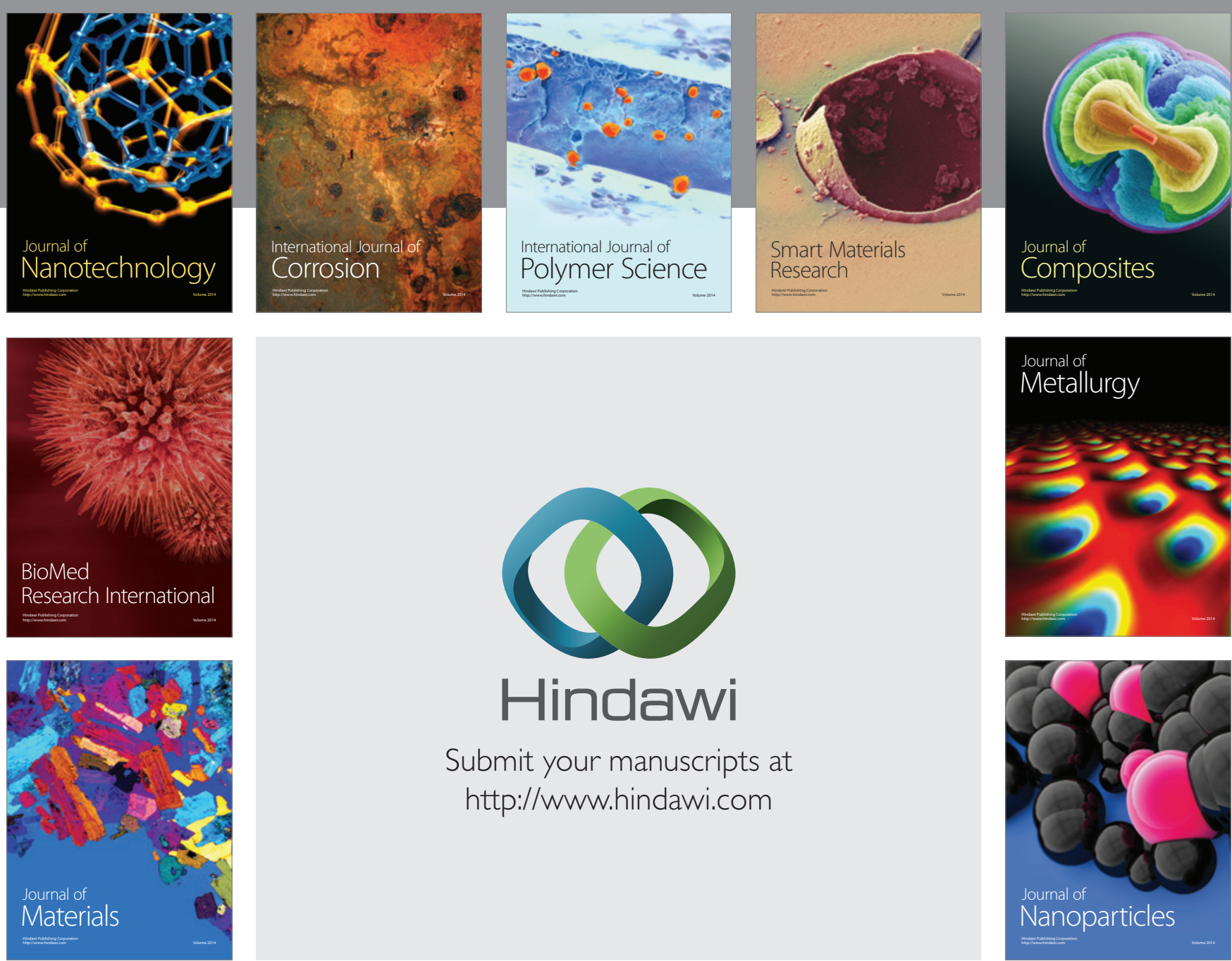

\section{Hindawi}

Submit your manuscripts at

http://www.hindawi.com

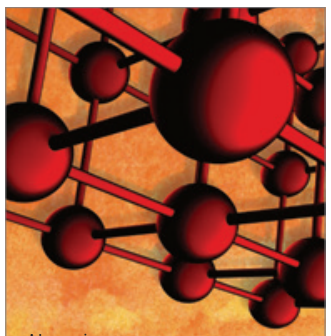

Materials Science and Engineering
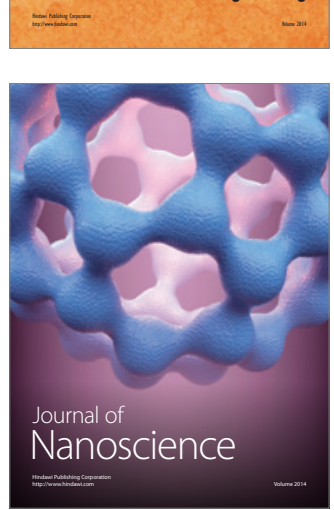
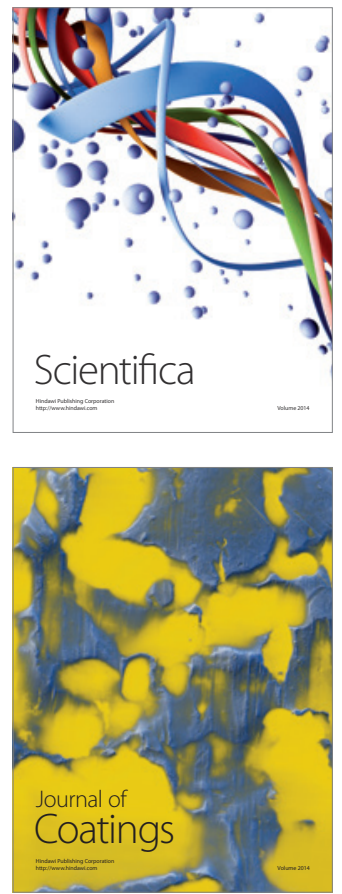
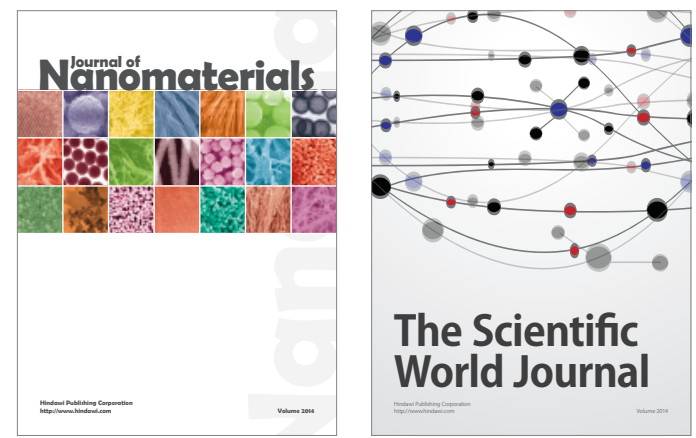

The Scientific World Journal
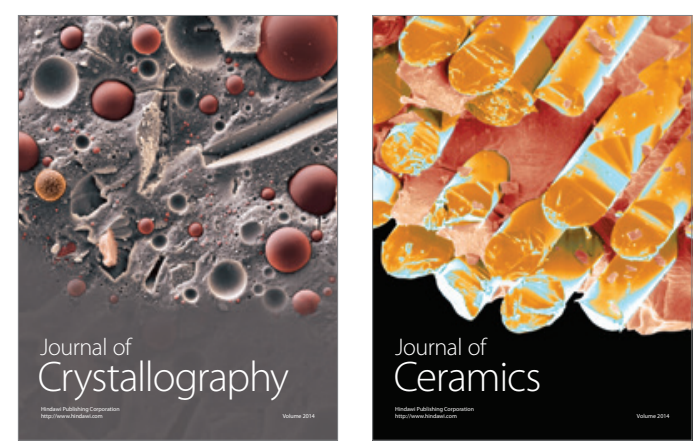
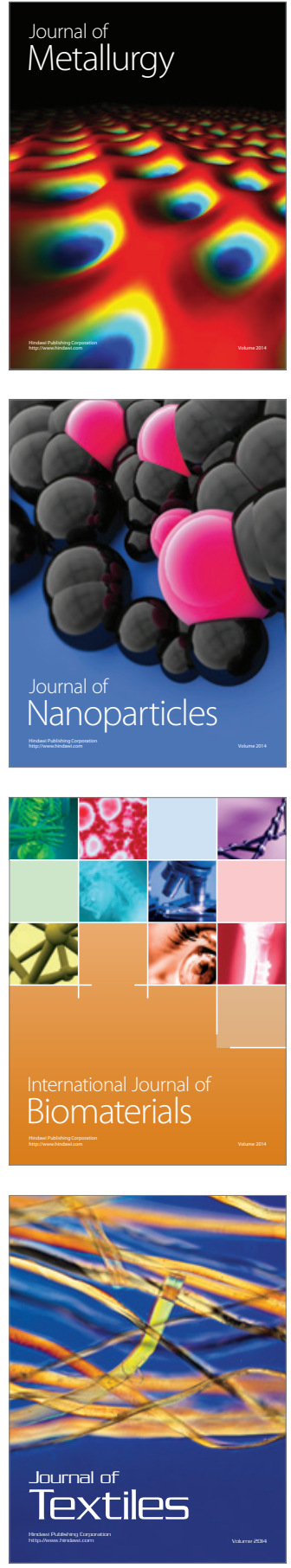